It is plain enough that there are serious practical difficulties in the way of such courses. The chief one is in the amount of time required from the instructor for their successful management. It not only requires that the instructor should have a complete acquaintance with his subject, but requires a constant personal supervision and thought, constant variations with different students, and requires that each instructor should plan his own course. A textbook is impossible, for it defeats its own end; or, if one instructor should write a book for his own class, it would be useless for others. Indeed, it is hardly possible to have any definite course; the aim being that each student should be brought in contact with the principles of nature as best suits his own ability, and not that the class as a whole should go over a regular course. Such work is by far the most difficult sort of teaching; and with the present small faculties of many of our colleges, and the inadequate training of many of the professors, it is practically impossible. But happily the faculties are growing larger, and more and more attention is being paid to selecting instructors fitted for their departments by previous training. Fewer hours of recitation-work are demanded, and more time is left to our instructors for thought and personal teaching. In many places can be seen a constant growth of this personal contact of instructor and student, and as fast as it grows we see the routine work of classes replaced by the work of students as individuals.

Along this line, then, we may look for the future development of sciences in the American college. We may hope for an increase in the amount of original investigation; but this must come chiefly from the instructors and graduate students, and it will then serve as an inspiration to the college. We may look for larger laboratories, more apparatus, and greater facilities for practical work on the part of large classes of students; but this will be insufficient unless we see at the same time an increase in the corps of instructors. Our boards of instructors should be large enough to make possible some personal supervision of the students, so that the individual will not become swallowed up in the mass, and large enough to allow to the instructors some time for research, by which means alone they can keep apace with the times. The great demand of higher education in this country is, therefore, not for more colleges or more buildings, but for more money devoted to instruction.

H. W. ConN.

\section{THE FUNCTION AND CONDUCT OF EXAMINATIONS.}

THE professors of a German university do not assign the student lessons, or require him to hear lectures. When the time comes to grant or refuse him the degree, their sole sources of information as to his fitness to receive it are, the thesis that he hands in, and the examination to which he is subjected. As respects time, this is a system of unlimited election. That it develops splendid qualities in the student ; that it is very grateful to young men who love freedom and hate task-work; and that, together with the other features of the German system, it produces scholars eminent in every branch of scholarship, - are well-known facts. In a German university, stated work is at a minimum, and the examination at a maximum, as a test of proficiency.

At the opposite end of the scale are the primary schools, in the strictest sense of that term. Here no election of work or time can be allowed beyond what extra-school conditions call for. 'Cutting' is absolutely inadmissible. The teacher cannot wait until the end of the term or month, or even day, to discover what the pupil knows : he must prescribe work every day, and, at the beginning, every hour, and then see that the work is done. This is a maximum of lesson, and a minimum of examination.

So far, all is plain and easy. But the moment that we enter the grades of school-work lying between these extremes, we meet a wide difference of opinion, and encounter serious practical difficulties. Here Germany has nothing to teach us. The method of the primary school is then continued to the end of the gymnasium course, when the student plunges at once into the fullest university liberty. The proper end is, rather, progressively to lift the pupil above the task-work level, to give him freedom, and to make him self-reliant. Two opposite tendencies are now very observable in the United States :-
I. A considerable number of colleges are allowing a limited election of time. This means, if a proper regimen is maintained, less dependence upon the daily recitation, and more dependence upon the examination.

2. In the intermediate public-school grades there is a diminishing dependence upon the examination, and an increasing dependence upon the daily work, particularly when the time comes to make the promotions: in fact, this tendency is declaring itself all along the public-school line.

These tendencies are both good; something of the freedom and enthusiasm of the university is finding its way into the college; and there is a manifest slackening of the high public-school tension of a few years ago, that was brought about by the abuse of examinations. Good results may be expected from both these movements.

The adjustment of requirement and election, of stated lessons and examinations, above the primary grades and below the college, or possibly the university, is a problem that every teacher and superintendent will be called upon to solve anew. The elements will vary, and no formula can be given. The solution in a given case will depend upon the facts that condition the home, the school, and even the individual pupil. It is often urged against examinations that they promote cramming. Teachers who have to solve this problem will do well to remember that they also tend to prevent cramming. Pupils cram for the daily recitation as well as for the examination; and as the daily recitation tends to check cramming for the one purpose, so the examination tends to check it for the other purpose.

B. A. Hinsdale.

I AM asked to write a very brief article on the function and conduct of examinations. By examinations is meant a formal set of questions answered in writing. Among the useful purposes which can be subserved by such tests are the following:-

I. They may serve as a stimulus or incentive to study. Students who know that at some period of their work they will be required to give written answers to questions based on the work done are likely to be more attentive, industrious, and interested in their work.

2. They encourage thoroughness. Those who prepare for an oral recitation may depend upon chance, or artifice, or favoritism, to help them through ; but a searching examination, calling for exact written statements, is another matter, and demands better preparation.

3. They afford an opportunity, in some instances, for a review of the whole subject passed over during the term.

4. They are often valuable as an exercise in English composition, calling as they do for clear, concise, comprehensive statements.

5. They are a revelation to the pupils of their own ability and attainments, as well as of their weakness and defects.

6. They call for concentration of mind, sustained mental effort, and a ready use of one's resources, which is a valuable educational discipline.

7. They reveal to the teacher the results of his teaching, the failure or success of his methods, and thus afford an opportunity of modifying his work when necessary.

8. The tabulated results of a series of examinations, extending through several months or years, indicate with considerable certainty the student's trend of mind, habits of study, and scholarly development. These results are specially valuable to parents in deciding what is best for their children.

9. The results are helpful to superintendents and others in forming an opinion of the progress of the pupils, and the work of the teacher.

Io. They give to school-work a kind of dignity, increase the student's self-respect, and impart to the teacher's mind a judicial habit, freeing him from the great tendency to judge of his pupils by sentimental regard rather than by a critical judgment.

With these ends in view, how shall the examinations be conducted?

I. They should be an ordinary, and not an extraordinary, part of school machinery. If they are held only at the close of a term, or at the conclusion of a study, the students should be prepared for them by the character of the daily recitation, and by occasional 